\title{
Indications and timing to perform tracheostomy in COVID-19 patients in intensive care unit: a review
}

\author{
Santosh Kumar Swain*
}

Department of Otorhinolaryngology and Head and Neck Surgery, IMS and SUM hospital, Siksha "O" Anusandhan University, Bhubaneswar, Odisha, India

Received: 05 July 2021

Accepted: 07 August 2021

*Correspondence:

Dr. Santosh Kumar Swain,

E-mail: santoshvoltaire@yahoo.co.in

Copyright: (C) the author(s), publisher and licensee Medip Academy. This is an open-access article distributed under the terms of the Creative Commons Attribution Non-Commercial License, which permits unrestricted non-commercial use, distribution, and reproduction in any medium, provided the original work is properly cited.

\begin{abstract}
Coronavirus disease 2019 (COVID-19) is a fatal and evolving disease and associated with more complication such as respiratory failure and requirement of mechanical ventilation in intensive care unit (ICU). Tracheostomy is a commonly performed surgical procedure done at ICU for prolonged ventilation of the COVID-19 patients. The indications and timing to do tracheostomy on COVID-19 patients are controversial. The requirement of prolonged invasive mechanical ventilation in COVID-19 patients is placing to increased request to perform tracheostomy. The role of performing tracheostomy in COVID-19 patients is exactly not known. Currently, there is no clear-cut evidence for improvement of the clinical course of COVID-19 patients. However, it is confirmed that tracheostomy decreases the ICU stay. Tracheostomy is usually suggested for avoiding potential tracheal injury within 7 to 14 days. Currently, there is uncertainty for timing of tracheotomy, prognosis of the patients and safety of health care professionals. Enhanced personal protective equipment and optimized tracheostomy can make the procedure safe and beneficial in COVID-19 patients. The need of tracheostomy is increasing in current COVID-19 pandemic. We have to perform this surgical procedure in proper time with safe manner for benefit of the patients and health care professionals. This review article focuses on the indications and optimum timing for performing tracheostomy on COVID-19 patients in ICU.
\end{abstract}

Keywords: COVID-19, SARS-CoV-2, Timing of tracheostomy, Indications of tracheostomy, ICU

\section{INTRODUCTION}

COVID-19 is a fatal and highly infectious disease caused by severe acute respiratory syndrome coronavirus-2 (SARS-CoV-2) virus. ${ }^{1}$ The clinical manifestations of COVID-19 patients may vary from throat pain, fever and myalgia to severe respiratory problem like acute respiratory distress syndrome (ARDS) and even respiratory failure. ${ }^{2}$ Severe COVID-19 patients may require endotracheal intubation and mechanical ventilation to help their potential recovery and in about 4 to $5 \%$ of such patients, invasive mechanical ventilation is needed. ${ }^{3}$ To avoid complications of prolonged intubation, tracheostomy can be considered by health care professionals. Tracheostomy is one of the important surgical procedures done among the critical ill patients for prolonged ventilation. ${ }^{4}$ Tracheostomy is an aerosol producing surgery with high chance of transmission of infection for health care professionals. It has important implications in patient care and spread of infections. There are several guidelines and recommendations for performing tracheostomy in COVID-19 patients but the indications and exact timing for tracheostomy is variable and unclear. The timing of tracheostomy in OCVID-19 patients indicates the outcome of the patient care in ICU. Tracheostomy usually reduces the ICU stay in context to prolonged invasive mechanical ventilation where they suggested within 7 to 14 days avoiding complications like damage to the trachea. ${ }^{5}$ Performing tracheostomy in 
COVID-19 patients reduce duration of mechanical ventilation but its utility for recovery of COVID-19 patients is still not know. ${ }^{6}$ As tracheostomy is an aerosolgenerating procedure, it increases health care professional's exposure to COVID-19 infection, but the time of the viral load and transmission rate of this infection are not yet exactly known. The indications and exact timing of tracheostomy in COVID-19 patients are often pose challenges in front of surgeon and health care professionals which are associated with safety of patients and health care professionals.

There are not many studies for defining the indications and optimum time to perform tracheostomy on COVID-19 patients at ICU. Here, the aim of this review article is to discuss the indications and optimum timing for performing tracheostomy on the COVID-19 patients at the intensive care unit.

\section{METHODS OF LITERATURE SEARCH}

We performed a literature review for indications and optimum timing for performing tracheostomy in COVID19 patients during the current pandemic consisting data base of PubMed, Medline, SCOPUS and Google scholar search with the words COVID-19, SARS-CoV-2 and indications of tracheostomy and timing of tracheostomy. We reviewed the different current articles and recommendations from national and international medical societies and decisions from several government medical councils. This manuscript reviews the details of indications and optimum timing for performing tracheostomy along with epidemiology, preventive measures for transmission of infection. This manuscript presents a baseline from where further prospective trials for indications and optimum timing of tracheostomy could be designed and helpful as a spur for further research in the COVID-19 pandemic and so prevent transmission of infections to medical professions and other patients during this procedure.

\section{EPIDEMIOLOGY}

COVID-19 is a highly contagious disease of the respiratory system which occur by novel coronavirus SARS-CoV-2. ${ }^{7}$ SARS-CoV-2 is $\beta$-coronavirus, which is enveloped non-segmented positive sense RNA virus (subgenus sarbecovirus and orthocoronavirinae subfamily). ${ }^{8}$ This infection is a newly evolving public health crisis threatening the world. The first patient of COVID-19 infection was reported in Wuhan, China in late December 2019 by SARS-CoV-2 (severe acute respiratory syndrome corona virus 2) and now rapidly spreading worldwide. $^{9}$ World health organization (WHO) declared the COVID-19 infection as pandemic on March 11, $2020 .^{9}$ In the hospital setting, critically ill patients with respiratory failure often need endotracheal intubation and changed to tracheostomy in case of prolonged ventilation. ${ }^{9}$ The incubation of the COVID-19 infection is 1-14 days, mostly 3-7 days and the COVID-19 is contagious during the latency period. ${ }^{10}$ One study shows 4 to $5 \%$ of such severe COVID-19 patients need invasive mechanical ventilation. $^{10}$ In one study, $6.30 \%$ patients need tracheostomy during the COVID-19 outbreak. ${ }^{11}$ Study showing 7.3-32\% COVID-19 patients lead to revere respiratory failure or critical ill condition, where patient may subsequently need tracheostomy for different reasons. ${ }^{12,13}$ Patients with COVID-19 infections are likely to undergo tracheal intubation and mechanical ventilation support. Data from Europe showed that most critically ill patients, the duration of invasive ventilation can be up to 21 days. ${ }^{14}$ Guidelines for performing a tracheostomy are made to minimize duration of mechanical ventilation and duration of stay at ICU but its benefits towards recovery of patient from COVID-19 infection is not known. ${ }^{15}$

\section{TRACHEOSTOMY AND RISK OF INFECTIONS}

There are some procedures in COVID-19 patients, capable to generate aerosols such as non-invasive ventilation, tracheal intubation, tracheostomy and manual ventilation before intubating the patients. ${ }^{16}$ These aerosol generating procedures are usually associated with high chance of SARS transmission. ${ }^{16}$ SARS-CoV-2 is usually spread via droplet infection and contact, so careful attention must be made during airway. ${ }^{17}$ In patients with COVID-19 infection, prolonged intubation and mechanical ventilation often require tracheostomy. However, many clinicians avoid it because of the risk of transmission of infection during the procedure and also during the process of the care for patients afterwards. There is a universal agreement that performing tracheostomy on COVID-19 patient's result in increased chance of viral transmission to health care professionals and other patients nearby. So, tracheostomy is considered as one of the most high-risk surgical procedures in COVID-19 patients. To avoid transmission of infections to tracheostomy team and surrounding health care professionals, adequate preparations is required (Table 1). Percutaneous dilatational tracheostomy is a minimally invasive procedure and less chance of transmitting infections to health care professionals than open tracheostomy. ${ }^{18}$ However, in certain situations like unfavourable neck anatomy, thyroid gland enlargement and cicatricial contracture of neck are not suitable for percutaneous tracheostomy. In these situations, open tracheostomy is an inevitable choice and this open tracheostomy is more vulnerable to result secretion spatter and contribute nosocomial spread of viruses from patients to personnel in the operating room. At the time of tracheostomy procedure in a COVID-19 patient, meticulous care should be paid to the surgical and anaesthetic technique to reduce the crosscontamination and occupational infection among health care professionals. ${ }^{19}$ Tracheostomy provides several advantages to the patients such as improved comfort, decreased sedative, paralytic medical support and decreased dead space. Moreover, the tracheostomy also decreases airway resistance and decreasing the work of bearing optimizing the tracheal secretion control. ${ }^{20}$ 
Table 1: Preparation for performing tracheostomy on COVID-19 patients.

\begin{tabular}{|c|c|c|c|c|}
\hline Operating site & Operating team & Operating time & $\begin{array}{l}\text { During opening the } \\
\text { trachea }\end{array}$ & Nursing care \\
\hline $\begin{array}{l}\text { Isolation area with } \\
\text { negative pressure }\end{array}$ & $\begin{array}{l}\text { Full PPE, head cap } \\
\text { face shield Goggles }\end{array}$ & $\begin{array}{l}\text { Over } 14 \text { days after } \\
\text { tracheal intubation }\end{array}$ & Paralyze the patient & $\begin{array}{l}\text { Safe suction of the } \\
\text { secretions }\end{array}$ \\
\hline $\begin{array}{l}\text { Limited number of } \\
\text { persons involved }\end{array}$ & Double gloves & $\begin{array}{l}\text { When failure to } \\
\text { spontaneous } \\
\text { breathing trial (SBT) }\end{array}$ & $\begin{array}{l}\text { Push the endotracheal } \\
\text { tube cuff caudally for } \\
\text { avoiding air leakage }\end{array}$ & $\begin{array}{l}\text { Regular checking } \\
\text { of cuff pressure }\end{array}$ \\
\hline $\begin{array}{l}\text { Surgical equipment } \\
\text { should be ready }\end{array}$ & $\begin{array}{l}\text { Mask-N95, FFP3 or } \\
\text { FFP2 }\end{array}$ & Difficult intubation & $\begin{array}{l}\text { Hyper inflate the cuff of } \\
\text { the tube }\end{array}$ & Stoma care \\
\hline $\begin{array}{l}\text { Tracheostomy team } \\
\text { with expertise }\end{array}$ & $\begin{array}{l}\text { Gowns (Double } \\
\text { gown preferable) }\end{array}$ & Re-intubation & $\begin{array}{l}\text { Avoid electrocautery. } \\
\text { Smoke evacuated if } \\
\text { electrocautery used }\end{array}$ & $\begin{array}{l}\text { Staff should be } \\
\text { trained for the } \\
\text { airway } \\
\text { management }\end{array}$ \\
\hline
\end{tabular}

\section{INDICATIONS OF TRACHEOSTOMY}

Tracheostomy is a commonly performed surgical procedure in intensive care unit and helpful for weaning from ventilator support, enhance pulmonary toilet, increase patient comfort and routinely performed living activity, decrease laryngeal injury by endotracheal intubation and prevent long-term complications like subglottic or tracheal stenosis. ${ }^{21}$ However, the surgical indications of the tracheostomy are greatly affected by the general health condition of the patient, comorbidity, prognosis, staff experience and hospital resources. ${ }^{22}$ Tracheostomy is an important surgical procedure in current coronavirus disease 2019 (COVID-19) pandemic particularly those cases undergoing prolonged tracheal intubation. In current COVID-19 pandemic, the tracheostomy is usually performed in reverse transcription polymerase chain reaction (RT PCR) tested COVID-19 patient with prolonged mechanical ventilation. The progressive increase of the COVID-19 patients will expect more requirements of the orotracheal intubation and prolonged ventilation. In this clinical context of ICU, tracheostomy can be considered by health care professionals. Performing tracheostomy on COVID-19 patients or suspected patients for COVID-19 infection imposes challenges not only to otorhinolaryngologists but also to the entire health care team. If the tracheostomy is not an emergency, this can be reviewed by a multidisciplinary team and risk versus benefits of this surgery and also the associated health care team should be assessed. Unlike the bacterial pneumonia, COVID-19 patients present with dry cough and produce little mucus and secretions, so it makes tracheostomy for pulmonary toilet less critical. ${ }^{23}$ Study showed, patients with COVID19 infections and respiratory failure require ventilator support more than 4 weeks, which result in prolonged rehabilitation as well as severe critical illness and neuropathy. ${ }^{24}$ Performing tracheostomy on COVID-19 patients in ICU impose challenges on health care professionals including operating surgeon. Before performing surgical tracheostomy, this can be properly assessed for indications with effective out come and benefit for the patients. ${ }^{25}$ Tracheostomy is an effective and safe surgical procedure performed for patients with prolonged endotracheal intubation as in acute respiratory failure. The decision for performing tracheostomy in COVID-19 patients is often based on standard weaning procedure. ${ }^{26}$ However, the decision for performing tracheostomy should consider for both benefits of the patient and occupational infection of SARS-CoV-2 in health care professionals during the COVID-19 pandemic. In current COVID-19 pandemic, clinicians must carefully consider the indications of tracheostomy on patients with COVID-19 in the ICU.

\section{TIMING OF TRACHEOSTOMY}

The optimal timing to perform tracheostomy in COVID19 patients remains controversial and highly dependent on the hospital, region and country. Timing of tracheostomy is an important relation with safety of the patients and health care professionals. The recommendations for performing tracheostomy from international, multidisciplinary experts suggested that it should be done at least 10 days after endotracheal intubation in COVID19 patients. $^{27}$ Current data from Europe suggested that most of critically ill patients, the duration of invasive ventilation could go up to 21 days. ${ }^{28}$ In current COVID-19 pandemic, the critical cases have been defined by presence of respiratory failure requiring mechanical ventilation and treatment at ICU. ${ }^{29}$ One study suggested deferring tracheostomy after 21 days of intubation and suggested open surgical tracheostomy over percutaneous dilatational tracheostomy. ${ }^{30}$ Similarly New York head and neck society suggested a 14-day standard with mean (SD) of 10.6 days. ${ }^{31}$ Guidelines regarding exact timing of tracheostomy consider scarcity of ventilators and other resources in ICU. ${ }^{32}$ One study suggested no sooner than two to three weeks after endotracheal intubation, despite the fact that the long-term laryngotracheal complications may be seen in prolonged intubation. ${ }^{33}$

\section{PREVENTION OF INFECTIONS DURING TRACHEOSTOMY}

Severely COVID-19 patients have high chance for requirement of prolonged intubation, making tracheostomy a likely consideration. The contagious nature of COVID-19 infection results an additional risk of 
viral transmission to health care professionals which should be taken into consideration. Tracheostomy is an aerosol generating procedures and it increases the exposure of health care workers to COVID-19 infections. ${ }^{34}$ Performing the tracheostomy and post-tracheostomy care need a strategy which mitigates these risks and enhances the quality of patient care. The establishment of a surgical tracheostomy strategy, experienced surgical team and use of appropriate personal protective equipment (Figure 1) in each hospital is needed to prevent transmission of infection. $^{35}$

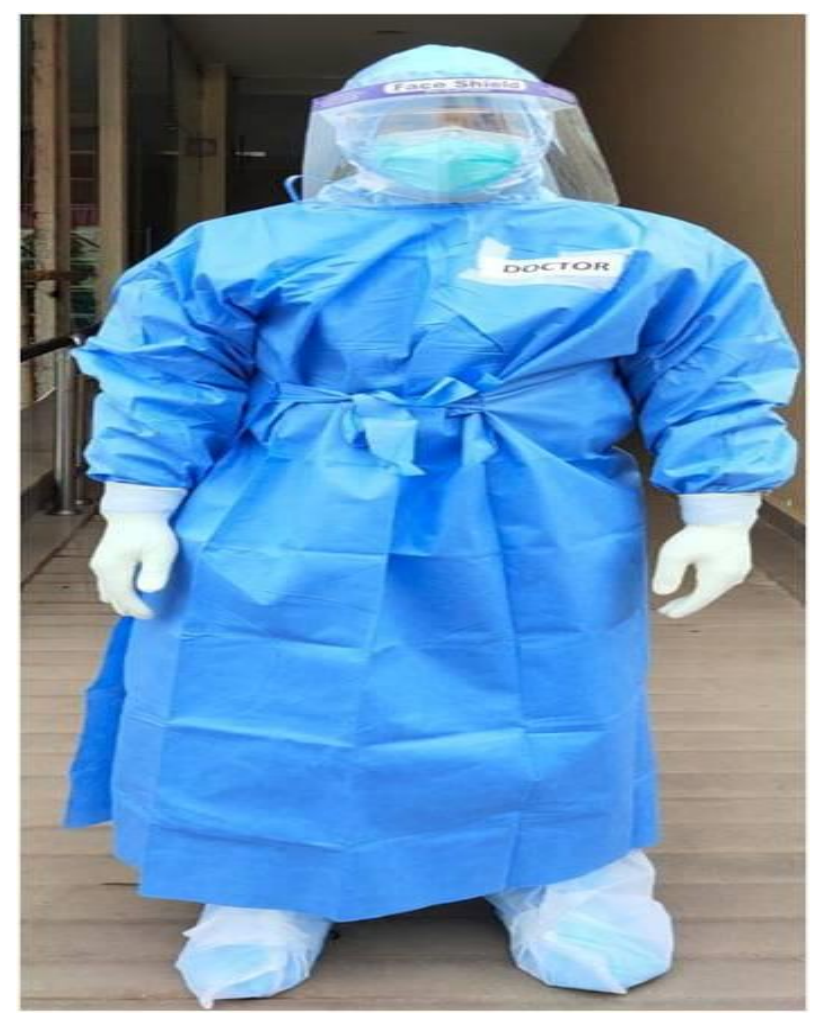

Figure 1: Surgeon with personal protective equipment (PPE) before performing tracheostomy.

To enhance the safety of tracheostomy in COVID-19 patients, a reusable type of instrument which consists of a transparent plastic shield with a sloping angled surface and a plastic drop attached to the top and side edges of the face shield. $^{36}$ Personal protective equipment (PPE) is considered as the primary means to decrease the transmission of SARS-CoV-2 virus to health care personnel. ${ }^{37}$ The surgical team should wear enhanced PPE including N-95 mask or FFP3, surgical cap, goggles and face shield, surgical gown (preferable double gown) and gloves (use of double nitrile gloves). Head cap and shoe covers are considered necessary safety of the health care workers. Tracheostomies should be performed in the ICU with negative pressure rooms for avoiding unnecessary transport of patients and repeated connections and disconnection of ventilator circuits during the transfer of patients. ${ }^{38}$ Senior or experiences staffs should perform the tracheostomy on COVID-19 patients. The number of health care professionals in this procedure should be kept to minimum number. Tracheostomy can be done as an open or percutaneous procedure, depending on the surgeon preference and patient factors. Two surgeons, one intensivist, one staff nurse of intensive care and two scrub nurses are ideally required to perform the tracheostomy. One scrub nurse should not enter the room but support the personnel in donning and doffing of the PPE and for preparation of surgical instruments. During tracheostomy, provide adequate sedation such paralysis which eliminates the risk of coughing during the procedure.$^{39}$ Ventilation should be paused (apnoea) at the end-expiration when making opening on the trachea where the ventilation circuit is disconnected. A non-fenestrated cuffed tracheostomy tube is better and it keeps the cuff inflated to stop the spread of the virus through the upper airway. Tracheostomy suctioning is should be done by a closed suction system with a viral filter. Heat moisture exchanger device can be used instead of tracheostomy collar at the time of the weaning for preventing virus spread or reinfection of the patient. The tracheostomy tube changing should be avoided until the viral load is as low as possible.

\section{CONCLUSION}

Presently COVID-19 is a challenge for global health care professionals. As the COVID-19 infection escalates, the staying of the patient in ICU is extended with ventilator. Acute respiratory distress syndrome and respiratory failure are serious complications of COVID-19 infection which need mechanical ventilation. Tracheostomy is needed in case of prolonged ventilation. Tracheostomy is an aerosolproducing procedure and associated high droplet and particle generating which pose risk for transmission of COVID-19 infection to health care providers. So, indications and timing of tracheostomy on COVID-19 patients is always challenging. There are still controversial for exact indications and timing for tracheostomy in COVID-19 patients. It is thus crucial for ICU teams and surgical personnel and they should be well prepared for performing the tracheostomy when required. Proper indications and optimum timing for performing tracheostomy are important decisions for health care professionals before the procedure. An experienced team of health care professionals is required for performing a safe tracheostomy in COVID-19 patients and to reduce the risk of occupational SARS-CoV-2 infection to them and others.

\section{Funding: No funding sources \\ Conflict of interest: None declared \\ Ethical approval: Not required}

\section{REFERENCES}

1. Zou L, Ruan F, Huang M, Liang L, Huang H, Hong Z et al. SARS-CoV-2 viral load in upper respiratory specimens of infected patients. $\mathrm{N}$ Engl J Med. 2020;382:1177-9.

2. Swain SK, Kumar S. Infection control measures during COVID-19 pandemic-An 
otorhinolaryngological and head-and-neck perspective. Indian $\mathbf{J}$ Health Sci Biomed Res. 2021;14(1):3-11.

3. David AP, Russell MD, El-Sayed IH, Russell MS. Tracheostomy guidelines developed at a large academic medical centre during the COVID-19 pandemic. Head Neck. 2020;42(6):1291-6.

4. Swain SK, Sahu MC, Choudhury J, Bhattacharyya B. Tracheostomy among paediatric patients: Our experiences at a tertiary care teaching hospital in Eastern India. Pediatria Pol-Pol J Paediatr. 2018;93:312-7.

5. Mattioli F, Fermi M, Ghirelli M, Molteni G, Sgarbi N, Bertellini E et al. Tracheostomy in the COVID-19 pandemic. Euro Arch of Oto-Rhino-Laryngol. 2020;277(7):2133-5.

6. Sommer DD, Engels PT, Weitzel EK, Khalili S, Corsten M, Tewfik MA et al. Recommendations from the CSO-HNS taskforce on performance of tracheotomy during the COVID-19 pandemic. J Otolaryngol-Head Neck Sur. 2020;49(1):1-4.

7. Swain SK, Behera IC. Managing pediatric otorhinolaryngology patients in coronavirus disease19 pandemic-A real challenge to the clinicians. Indian J Child Health. 2020;7(9):357-62.

8. Hsu LY, Chia PY, Lim JF. The novel coronavirus (SARS-CoV-2) pandemic. Ann Acad Med Singap. 2020;49(3):105-7.

9. Swain SK, Jena PP. Role of early tracheostomy for preventing ventilator associated pneumonia in intensive care unit: a review. Int J Otorhinolaryngol Head Neck Surg. 2021;7(6):1083-8.

10. Chen N, Zhou M, Dong X, Qu J, Gong F, Han Y et al. Epidemiological and clinical characteristics of 99 cases of 2019 novel coronavirus pneumonia in Wuhan, China: a descriptive study. Lancet. 2020;395(10223):507-13.

11. Chee VW, Khoo ML, Lee SF, Lai YC, Chin NM. Infection control measures for operative procedures in severe acute respiratory syndrome-related patients. Anesthesiology. 2004;100(6):1394-98.

12. Wang D, Hu B, Hu C, Zhu F, Liu X, Zhang J et al. Clinical characteristics of 138 hospitalized patients with 2019 novel coronavirus-infected pneumonia in Wuhan, China. JAMA. 2020;323(11):1061-9.

13. Huang C, Wang Y, Li X, Ren L, Zhao J, Hu Y et al. Clinical features of patients infected with 2019 novel coronavirus in Wuhan, China. The lancet. 2020;395(10223):497-506.

14. Pedersen HP, Hildebrandt T, Poulsen A, Uslu B, Knudsen HH, Roed J et al. Initial experiences from patients with COVID-19 on ventilatory support in Denmark. Dan Med J. 2020;67(5):1-4.

15. Takhar A, Walker A, Tricklebank S, Wyncoll D, Hart $\mathrm{N}$, Jacob $\mathrm{T}$ et al. Recommendation of a practical guideline for safe tracheostomy during the COVID19 pandemic. Eur Arch Otorhinolaryngol. 2020;21:1-12.

16. Swain SK, Jena PP, Pani SR. Impact of COVID-19 infections in the clinical practices of otorhinolaryngology and head and neck surgery: A review. Apollo Medi. 2021;18(5):21-6.

17. Swain SK, Acharya S, Sahajan N. Otorhinolaryngological manifestations in COVID-19 infections: An early indicator for isolating the positive cases. J Scientific Society. 2020;47(2):63-8.

18. Mehta C, Mehta Y. Percutaneous tracheostomy. Ann Card Anaesth. 2017;20:19-25.

19. Hiramatsu M, Nishio N, Ozaki M, Shindo Y, Suzuki $\mathrm{K}$, Yamamoto $\mathrm{T}$, et al. Anesthetic and surgical management of tracheostomy in a patient with COVID-19. Auris Nasus Larynx. 2020;47(3):472-6.

20. Swain SK, Acharya S, Das S. Social impact of tracheostomy: Our experiences at a tertiary care teaching hospital of Eastern India. J Sci Soc. 2020;47(3):148-52.

21. Swain SK, Behera IC, Sahu MC. Bedside open tracheostomy at intensive care unit-our experiences of 1000 cases at a tertiary care teaching hospital of eastern India. Egypt J Ear, Nose, Throat and Allied Sci. 2017;18(1):49-53.

22. Swain SK, Behera IC, Ananda N. Pediatric tracheostomy in COVID-19 pandemic: a review. Int J Contemp Pediatr. 2021;8(3):602-8.

23. Xu Z, Shi L, Wang Y, Zhang J, Huang L, Zhang C et al. Pathological findings of COVID-19 associated with acute respiratory distress syndrome. Lancet Resp Med. 2020;8(4):420-2.

24. Israelsen SB, Kristiansen KT, Hindsberger B, Ulrik $\mathrm{CS}$, Andersen O, Jensen $\mathrm{M}$ et al. Characteristics of patients with COVID-19 pneumonia at Hvidovre Hospital, March-April 2020. Dan Med J. 2020;67(6):1-4.

25. Swain SK, Das S, Padhy RN. Performing tracheostomy in intensive care unit-A challenge during COVID-19 pandemic. Siriraj Med J. 2020;72(5):436-42.

26. Schmidt GA, Girard TD, Kress JP, Morris PE, Ouellette DR, AL-hazzani W et al. Liberation from mechanical ventilation in critically ill adults: executive summary of an official American College of Chest Physcians/American Thoracic Society Practice Guideline. Chest. 2017;151(1):160-5.

27. McGrath BA, Brenner MJ, Warrillow SJ, Pandian V, Arora A, Cameron TS et al. Tracheostomy in the COVID-19 era: global and multidisciplinary guidance. Lancet Respir Med. 2020;8(7):717-25.

28. Volo T, Stritoni P, Battel I, Zennaro B, Lazzari F, Bellin $\mathrm{M}$ et al. Elective tracheostomy during COVID19 outbreak: to whom, when, how? Early experience from Venice, Italy. Euro Arch Oto-Rhino-Laryngol. 2021;278(3):781-9.

29. Huang C, Wang Y, Li X, Ren L, Zhao J, Yi H et al. Clinical features of patients infected with, novel coronavirus in Wuhan. China Lancet. 2019;395(10223):497-506.

30. Chao TN, Harbison SP, Braslow BM, Hutchinson CT, Rajasekaran K, Go BC et al. Outcomes After Tracheostomy in COVID-19 Patients. Ann surg 2020;272(3):181-6. 
31. Miles BA, Schiff B, Ganly I, Ow T, Cohen E, Genden $E$ et al. Tracheostomy during SARS-CoV-2 pandemic: Recommendations from the New York Head and Neck Society. Head neck. 2020;42(6):128290.

32. Michetti CP, Burlew CC, Bulger EM, Davis KA, Spain DA. Critical Care and Acute Care Surgery Committees of the American Association for the Surgery of Trauma. Performing tracheostomy during the Covid-19 pandemic. Trauma Surg Acute Care Open. 2020;5(1):e000482.

33. Wei WI, Tuen HH, Ng RW, Lam LK. Safe tracheostomy for patients with severe acute respiratory syndrome. The Laryngoscope. 2003;113(10):1777-9.

34. Swain SK, Sahu MC, Choudhury J, Bhattacharyya B. Tracheostomy among paediatric patients: Our experiences at a tertiary care teaching hospital in Eastern India. Pediatr Pol. 2018;93:312-7.

35. Swain SK, Das A, Behera IC, Bhattacharyya B. Tracheostomy among pediatric patients: A review. Indian Journal of Child Health. 2018;5(9):557-61.
36. Goto Y, Yamamoto T, Ozaki M. Aerosol shield and tent for health-care workers' protection during the coronavirus disease 2019 pandemic. Acute Med Surg. 2020;7(1):550-2.

37. Swain SK, Acharya S. Bedside tracheostomy on COVID-19 patients in the intensive care unit: A retrospective study. Airway. 2021;4(1):28-34.

38. Sahu A, Swain SK, Das SR. Performing Bedside Surgical Tracheostomy On COVID-19 Patients at Intensive Care Unit-Our Experiences At A Tertiary Care Indian Teaching Hospital. Euro J Mol Clin Med. 2020;7(11):1208-17.

39. Swain SK, Sahu A. Performing tracheostomy on COVID-19 pediatric patients at intensive care unit: Our experiences. Indian J Health Sci and Biomed Res. 2021;14(1):131-6.

Cite this article as: Swain SK. Indications and timing to perform tracheostomy in COVID-19 patients in intensive care unit: a review. Int $\mathrm{J} \mathrm{Adv}$ Med 2021;8:1450-5. 